\title{
PENGARUH ELECTRONIC ROAD PRICING TERHADAP VOLUME LALU LINTAS PADA RUAS JALAN BLOK M - KOTA
}

\author{
Randy Senapati ${ }^{1}$ dan Najid $^{2}$ \\ ${ }^{1}$ Program Studi Sarjana Teknik Sipil, Universitas Tarumanagara, Jl. Letjen S. Parman No. 1 Jakarta Barat \\ Randy.325130005@stu.untar.ac.id \\ ${ }^{2}$ Program Studi Sarjana Teknik Sipil, Universitas Tarumanagara, Jl. Letjen S. Parman No. 1 Jakarta Barat \\ Najid2009@yahoo.com
}

Masuk: 17-01-2020, revisi: 14-02-2020, diterima untuk diterbitkan: 14-02-2020

\begin{abstract}
Electronic road pricing is a prepaid road which is used to decrease the traffic volume with put on the on board unit device as the payment tool. The high number of vehicle volume at Jakarta become one of the main reason of electronic road pricing used at the traffic. On this research will be discussed about the condition of Blok M-Kota traffic situation, this road is a main access for people especially to work. to analyze the vehicle volume will be using direct observation method to get the volume, velocity and intensiveness of the traffic. Direct observation will be used to watch vehicle such as motorcycle, light vehicle and weight vehicle. With observation data we will get graphic about the connectivity between velocity and intensiveness that will be modified with questionnaire. Questionnaire data will be spreaded out to get the percentage of decreased volume and estimated price for electronic road pricing. the price and time will be processed with analysis of variance method (ANOVA) asissted with SPSS program. With this research, we expected to learn the electronic road pricing with most efficient price to decrease the vehicle volume at Blok $M$ - Kota road.
\end{abstract}

Keywords: Blok M; Kota; Electronic Road Pricing; SPSS

\begin{abstract}
ABSTRAK
Electronic Road Pricing adalah jalan berbayar yang digunakan untuk mengurangi volume lalu lintas dengan cara memasangkan alat On Board Unit sebagai alat pembayarannya. Tingginya volume kendaraan di Jakarta menjadi alasan utama Electronic Road Pricing digunakan pada lalu lintas. Pada penelitian ini, dibahas mengenai kondisi lalu lintas Blok M - Kota, ruas jalan ini merupakan akses pengguna jalan untuk menuju perkantoran dan tempat wisata. Untuk menganalisa volume kendaraan akan digunakan metode observasi langsung untuk mendapatkan volume, kecepatan dan kepadatan lalu lintas. Observasi langsung dilakukan dengan memperhatikan kendaraan bermotor roda dua, kendaraan ringan dan kendaraan berat. Dengan data observasi akan didapat grafik hubungan antara kecepatan dan kedapatan yang akan dimodifikasi dengan data kuesioner. Data kuesioner disebar untuk mendapatkan persentase penurunan volume dan perkiraan harga Electronic Road Pricing untuk mengurangi volume lalu lintas. Pilihan harga dan waktu akan diolah dengan metode analysis of variance (ANOVA) dengan dibantu program SPSS. Diharapkan pada analisis penelitian ini dapat mengetahui biaya Electronic Road Pricing yang paling efisien untuk mengurangi volume kendaraan pada ruas jalan Blok M - Kota.
\end{abstract}

Kata kunci: Blok M; Kota; Electronic Road Pricing; SPSS

\section{PENDAHULUAN}

\section{Latar belakang}

Transportasi adalah kegiatan pemindahan barang dan penumpang dari suatu tempat ke tempat lain. Transportasi sudah menjadi sesuatu hal yang penting dalam kehidupan manusia khususnya dalam mengefisienkan waktu untuk mencapai suatu tempat. Tidak hanya untuk mengefisienkan waktu pemindahan manusia, namun membantu juga dalam pemindahan barang - barang. Di seluruh negara transportasi merupakan permasalahan yang sudah berlangsung lama 
dan semakin parah. Tingginya mobilitas penduduk dan barang menjadi penyebab utama pertumbuhan penggunaan transportasi, baik kendaraan pribadi maupun kendaraan umum. DKI Jakarta merupakan salah satu kota yang membutuhkan transportasi yang memadai. Berdasarkan Ditlantas Polda Metro Jaya Provinsi DKI Jakarta 2017, jumlah kendaraan bermotor yang terdaftar di Jakarta sudah sebanyak 18.006.404 unit kendaraan dan memiliki angka pertumbuhan $5,35 \%$ per tahun.

Ruas jalan Blok M - Beos (Kota) merupakan jalan utama untuk menuju daerah bisnis, sekolah dan pusat perbelanjaan. Jalan Blok M - Beos Memiliki Panjang 12,9 km dan memiliki beberapa kendaraan umum yang dapat digunakan untuk melewati jalan ini yaitu PPD P1, PPD AC - PAC 801 dan Transjakarta Koridor 1. Ditambah dengan transportasi online memudahkan penduduk untuk memilih transportasi yang ingin digunakan tidak hanya transportasi umum.

Transportasi online adalah salah satu alasan jalan di DKI Jakarta menjadi ramai dan tidak terkendali. Menurut $D R$. Bambang Susantono, penambahan jumlah unit transportasi online yang cenderung cepat dan undang - undang yang mengatur belum selesai disusun menjadi masalah utama dalam permasalahan ini. Peningkatan kapasitas kendaraan pada saat jam - jam sibuk (rush hour traffic) dibeberapa tempat seperti daerah - daerah bisnis, pusat perbelanjaan dan sekolah akan menjadi permasalahan yang berpotensi menimbulkan konflik lalu lintas. Banyaknya kendaraan dibandingkan panjang jalan menimbulkan kemacetan di sepanjang jalan, perempatan jalan dan perlintasan kereta api.

Perlu dilakukan berbagai kebijakan peraturan untuk mengatasi masalah ini seperti 3 in 1, ganjil genap, under pass dan fly over. Dan salah satu metode yang akan diterapkan yaitu Electronic Road Pricing (ERP) yang akan menggantikan 3 in 1. Penerapan 3 in 1 dinilai memiliki kelemahan tersendiri seperti inkonsistensi penindakan pelanggaran aturan 3 in 1 , jumlah petugas yang tidak memadai dan kemunculan joki.

Electronic Road Pricing (ERP) adalah metode yang diterapkan di Hongkong sejak awal tahun 80an dan diadopsi oleh Singapura pada September 1998. ERP digunakan untuk tujuan tertentu yaitu untuk mengurangi angka kepadatan lalu lintas, mengurangi polusi, agar penduduk menggunakan kendaraan umum, meningkatkan kecepatan dan menambah pendapatan di suatu daerah atau negara. Badan Pengelola Transportasi Jabodetabek (BPTJ) merupakan organisasi yang terus mendorong Pemerintah Provinsi DKI agar segera menerapkan Electronic Road Pricing. Rencananya ERP akan ada di sepanjang Jalan Jendral Sudirman dan Jalan MH Thamrin.

Sebelum melewati rute yang terdapat ERP kendaraan roda 4 harus memiliki alat on board unit (OBU) yang berharga sekitar Rp 200.000 sampai Rp 250.000 per unit (berita satu. Jumat, 9 Februari 2018 p.1). Hingga saat ini harga untuk lewat jalur ERP masih belum dipastikan namun biaya antara mobil dan motor akan berbeda dan akan diatur oleh Perda (Peraturan Daerah). Pada proses lelang jalan berbayar Electronic Road Pricing sudah selesai pada tahap prakualifikasi dan sudah ada tiga peserta yang lolos yaitu PT Bali Towerindo Sentra, Kapsch Traffic Com AB dan Qfree ASA (Berita satu. Senin, 12 November 2018 p.1).

\section{Rumusan masalah}

1. Bagaimana dampak Electronic Road Pricing terhadap penggunaan transportasi pribadi dan kendaraan umum.

2. Berapa tarif Electronic Road Pricing yang efektif untuk mengurangi kemacetan.

\section{Tujuan penelitian}

1. Untuk mengetahui perkiraan harga Electronic Road Pricing yang efektif untuk mengurangi kemacetan.

2. Untuk mengetahui kondisi pengguna transportasi pribadi dan transportasi online jika diberlakukannya Electronic Road Pricing.

3. Untuk mengetahui kondisi jalan jika diberlakukannya Electronic Road Pricing.

\section{Electronic Road Pricing (ERP)}

Electronic Road Pricing (ERP) adalah metode yang diterapkan di Hongkong sejak awal tahun 80an dan diadopsi oleh Singapura pada September 1998. ERP digunakan untuk tujuan tertentu yaitu untuk mengurangi angka kepadatan lalu lintas, mengurangi polusi, agar penduduk menggunakan kendaraan umum, meningkatkan kecepatan dan menambah pendapatan di suatu daerah atau negara. Electronic Road Pricing adalah jalan berbayar dimana kendaraan akan terkena biaya bila memasuki area yang dipasang alat ini. Berbeda dengan jalan tol, jalan dengan alat Electronic Road Pricing tidak harus menunggu palang otomatis, hanya dengan melewati sudah dapat terbayar dan melewati jalan. Electronic 
Road Pricing di Jakarta bekerja bila kendaraan memiliki OBU (On Board Unit) dan akan terkena biaya bila melewati kawasan ini.

\section{Dasar hukum penerapan Electronic Road Pricing (ERP) di DKI Jakarta}

Electronic Road Pricing harus memenuhi syarat dan dasar hukum yang kuat untuk bisa diluncurkan. Dasar hukum yang dapat menopang Electronic Road Pricing yaitu Undang - undang Nomor 22 tahun 2009 tentang lalu lintas dan angkutan jalan pasal 133 ayat 3 Pembatasan lalu lintas dapat dilakukan dengan pengenaan retribusi pengendalian lalu lintas yang diperuntukan bagi peningkatan kinerja lalu lintas dan peningkatan pelayanan angkutan umum dan Rancangan Peraturan Pemerintah pasal 472 tahun 2010 tentang lalu lintas dan angkutan jalan.

\section{Metode regresi linear berganda}

Regresi linier sederhana adalah salah satu metode analisi statistik yang membahas hubungan dari dua variabel yaitu satu variabel X dan satu variabel Y. Sebagai contoh, kita dapat melihat hubungan antara biaya periklanan (X) dan hasil penjualan (Y). Menurut perkiraan hubungan tersebut sangat mungkin, bisa jadi periklanan bukanlah satu-satunya penentu tinggi rendahnya hasil penjualan. Selain biaya periklanan bisa saja terdapat variabel lain yang dapat memengaruhi hasil penjualan. Sehingga bisa kita katakan bahwa ada banyak variabel (X) yang akan memengaruhi variabel penjualan (Y). Maka dalam hal ini persamaan regresi linier berganda dapat digunakan untuk melihat hubungan dari satu variabel Y dan beberapa variabel X. Persamaann / rumus regresi linier berganda adalah sebagai berikut :

$$
\begin{gathered}
\hat{Y}=b_{0}+b_{1} \mathrm{X}_{1}+\mathrm{b}_{2} \mathrm{X}_{2}+\ldots .+\mathrm{b}_{\mathrm{k}} \mathrm{X}_{\mathrm{k}} \\
\hat{Y}_{t}=\mathrm{b}_{0}+\mathrm{b}_{1} \mathrm{X}_{1 \mathrm{i}}+\mathrm{b}_{2} \mathrm{X}_{2 \mathrm{i}}+\ldots . .+\mathrm{b}_{\mathrm{k}} \mathrm{X}_{\mathrm{ki}}
\end{gathered}
$$

dengan $\mathrm{i}=1,2, . . \mathrm{n}, \mathrm{Y}^{\wedge}=$ variabel terikat $\mathrm{Y}, \mathrm{X}=$ Variabel bebas, $\mathrm{b}_{0}=$ Konstanta, $\mathrm{b}_{\mathrm{i}}=$ Koefisien Penduga

\section{METODE PENELITIAN}

Pada penelitian ini, harus dibuat jalannya penelitian yang akan menjadi panduan dalam pelaksanaan penelitian agar penelitian dapat dijalankan dengan baik dan sistematis. Awal penelitian akan dilakukan pengamatan secara langsung di tempat, penyebaran kuesioner dengan kuesioner berjenis stated preference. Angka penggunaan kendaraan akan diperhitungkan dan dibuat modelnya, lalu akan dibuat dalam grafik hubungan antara kecepatan, kepadatan, dan volume. Kemudian akan diidentifikasi masalah yang telah ada, lalu akan dilakukan pembuatan formulir survei yang akan di uji coba terlebih dahulu sebelum formulir survei sebagai kuesioner akhir. Pengambilan data yang akan diambil yaitu data primer. Dimana data primer yaitu data hasil pengamatan dan hasil dari penyebaran kuesioner dan wawancara. Dari data primer ini akan dibuat model transportasinya yaitu dari data hasil pengamatan dan kemudian akan di modifikasi dengan menggunakan hasil data kuesioner yang akan dibuat kembali model transportasinya. Pengambilan data hasil pengamatan akan didapatkan kecepatan, kepadatan, dan volume kendaraan. Pengambilan data kuesioner akan didapatkan jumlah pengguna yang akan berpindah moda karena adanya rekayasa jalan Electronic Road Pricing. Setelah menyelesaikan semua penelitian hingga akhir, dapat ditentukan harga Electronic Road Pricing yang sesuai pada ruas jalan Blok M - Kota dengan mempertimbangkan kecepatan, kapasitas dan volume jalan.

\section{Metode pengumpulan data}

Survei yang akan dilakukan dengan cara pengamatan langsung ditempat adalah salah satu metode primer dalam penelitian ini yang mencangkup banyak hal seperti kapasitas jalan, kecepatan rata - rata, volume lalu lintas, dan tingkat kepuasan pelayanan lalu lintas diruas jalan Thamrin, Sudirman dan Gajah Mada. Selain pengamatan secara langsung, survei ini didukung juga dengan survei wawancara atau kuesioner yang dimana hasil dari kuesioner ini akan digunakan untuk memodifikasi hasil survei pengamatan. Kuesioner menggunakan skala likert dimana kuesioner ini berisi tentang tingkat keinginan penggunaan jalan bila diberikan sistem jalan berbayar atau Electronic Road Pricing. Skala keinginan diukur dalam tingkat kepuasan dari keinginan meneruskan menggunakan kendaraan pribadi atau berganti moda perjalanan dengan menggunakan kerndaraan umum. Besarnya keinginan pengguna jalan untuk berpindah moda perjalanan akan menurunkan angka kapasitas dari hasil observasi. Pengumpulan data dengan kuesioner akan diolah dengan menganalisa sudut pandang pada pengguna jalan yang menggunakan jalan Blok $\mathbf{M}-$ Kota. Kemudian data tersebut akan dimasukan kedalam program SPSS. SPSS merupakan program yang akan menganalisa data statistik. 


\section{HASIL DAN PEMBAHASAN}

Lokasi jalan untuk survei lalu lintas yaitu Jalan Gajah Mada, Jalan M.H. Thamrin dan Jalan Jendral Sudirman. Lokasi ini dipilih karena merupakan salah satu lokasi yang memiliki angka kepadatan yang cukup tinggi dan dilewati oleh moda transportasi Umum seperti Transjakarta dan Mikrolet. Dengan adanya moda transportasi seperti Transjakarta dan Mikrolet ditargetkan untuk menjadi lokasiuntuk program Electronic Road Pricing (ERP) dan diharapkan angka kepadatan lalu lintas berkurang setelah program tersebut diberlakukan. Data diambil dengan menggunakan kuesioner secara langsung sebanyak 50 responden. Analisis ini akan memberikan gambaran seberapa besar perubahan lalu lintas bila Electronic Road Pricing telah dijalankan. Data yang diperoleh dari hasil kuesioner kemudian akan dikombinasikan dengan hasil pengamatan langsung. Data yang diperoleh dari wawancara kuesioner dan observasi lapangan, kemudian akan dibuat tabulasi dalam bentuk tabel. Untuk jawaban responden mengenai pemilihan tarif Electronic Road Pricing dan waktu perjalanan dan dapat dilihat pada tabel 1 dibawah ini.

Tabel 1. Hasil kuesioner pemilihan tarif ERP

\begin{tabular}{|c|c|c|c|c|c|c|}
\hline \multirow{3}{*}{ No. } & \multirow{2}{*}{\multicolumn{2}{|c|}{$\begin{array}{c}\text { Kondisi Perjalanan Setelah Penerapan } \\
\text { ERP }\end{array}$}} & \multicolumn{4}{|c|}{ Pilihan (beri tanda X) } \\
\hline & & & \multirow{2}{*}{$\begin{array}{c}\text { Pasti } \\
\text { memilih jalan }\end{array}$} & \multirow{2}{*}{$\begin{array}{c}\text { Mungkin } \\
\text { memilih jalan }\end{array}$} & \multirow{2}{*}{$\begin{array}{c}\text { Mungkin } \\
\text { tidak } \\
\text { memilih jalan }\end{array}$} & \multirow{2}{*}{$\begin{array}{l}\text { Tidak akan } \\
\text { memilih jalan }\end{array}$} \\
\hline & Tarif ERP (Rp) & Waktu perjalanan * & & & & \\
\hline 1 & 15.000 & Lebih cepat 10 menit & 18 & 15 & 9 & 8 \\
\hline 2 & 30.000 & Lebih cepat 20 menit & 17 & 22 & 11 & 0 \\
\hline 3 & 40.000 & Lebih cepat 30 menit & 14 & 14 & 16 & 6 \\
\hline 4 & 50.000 & Lebih cepat 40 menit & 1 & 1 & 21 & 27 \\
\hline 5 & 60.000 & Lebih cepat 45 menit & 0 & 0 & 1 & 49 \\
\hline 6 & 65.000 & Lebih cepat 50 menit & 0 & 0 & 1 & 49 \\
\hline
\end{tabular}

Pada setiap ruas jalan akan dilakukan observasi langsung selama 3 kali yaitu pada pukul 06.00, 12.00 dan 17.00 dengan rentang waktu 15 menit yang dilakukan selama 2 jam. Data yang disajikan akan dibedakan menjadi 2 yaitu data motor dan data mobil. Nilai dari hambatan samping akan digunakan untuk mencari nilai kapasitas lalu lintas. Besarnya nilai hambatan samping akan mempengaruhi nilai kapasitas jalan. Nilai kapasitas ini akan digunakan untuk mengetahui apakah kapasitas lalu lintas akan berubah jika diberlakukannya Electronic Road Pricing. Pada data yang disajikan akan menunjukan jumlah kendaraan roda dua dan kendaraan roda empat (termasuk kendaraan berat) yang lewat dengan jarak $200 \mathrm{~m}$ dalam waktu 15 menit dan rata - rata waktu tempuh kendaraan. Hasil dapat dilihat pada tabel 2, tabel 3 dan tabel 4 .

Tabel 2. Hasil observasi langsung arah Thamrin - Monas jam $06.00-08.00$

\begin{tabular}{|c|c|c|c|c|c|c|c|c|c|}
\hline \multirow[b]{2}{*}{ Waktu } & \multirow{2}{*}{$\begin{array}{c}\text { Jarak } \\
(\mathrm{m})\end{array}$} & \multicolumn{2}{|c|}{ Motor } & \multicolumn{2}{|l|}{ Mobil } & Bus/Truck & \multirow[b]{2}{*}{ Q } & \multirow[b]{2}{*}{$\overline{\mathrm{V}}$} & \multirow[b]{2}{*}{$\mathrm{Q} / \overline{\mathrm{V}}$} \\
\hline & & Jumlah & $\begin{array}{c}\mathrm{T} \\
(\mathrm{s})\end{array}$ & Total & $\begin{array}{c}\mathrm{T} \\
(\mathrm{s})\end{array}$ & Total & & & \\
\hline $06.00-06.15$ & 200 & 847 & 16 & 294 & 17 & 2 & 1143 & 43,67647 & 26,169697 \\
\hline $06.15-06.30$ & 200 & 932 & 16 & 301 & 17 & 2 & 1235 & 43,67647 & 28,2760943 \\
\hline $06.30-06.45$ & 200 & 921 & 16 & 346 & 18 & 3 & 1270 & 42,5 & 29,8823529 \\
\hline $06.45-07.00$ & 200 & 987 & 15 & 424 & 18 & 5 & 1416 & 44 & 32,1818182 \\
\hline $07.00-07.15$ & 200 & 1064 & 16 & 456 & 18 & 4 & 1524 & 42,5 & 35,8588235 \\
\hline $07.15-07.30$ & 200 & 1000 & 17 & 444 & 19 & 4 & 1448 & 40,12384 & 36,0882716 \\
\hline $07.30-07.45$ & 200 & 1034 & 17 & 414 & 19 & 3 & 1451 & 40,12384 & 36,1630401 \\
\hline $07.45-08.00$ & 200 & 956 & 16 & 471 & 19 & 3 & 1430 & 41,44737 & 34,5015873 \\
\hline
\end{tabular}


Tabel 3. Hasil observasi langsung arah Thamrin - Monas jam $12.00-14.00$

\begin{tabular}{cccccccccc}
\hline \multirow{2}{*}{ Waktu } & \multirow{2}{*}{$\begin{array}{c}\text { Jarak } \\
(\mathrm{m})\end{array}$} & \multicolumn{2}{c}{ Motor } & Mobil & \multicolumn{3}{c}{ Bus/Truck } & Q & \multicolumn{1}{c}{ T } \\
& & Jumlah & Total & $\begin{array}{c}\mathrm{T} \\
(\mathrm{s})\end{array}$ & Total & & $\overline{\mathrm{V}}$ & $\bar{Q} / \overline{\mathrm{V}}$ \\
\hline $12.00-12.15$ & 200 & 754 & 16 & 271 & 19 & 7 & 1032 & 41,44737 & 24,8990476 \\
\hline $12.15-12.30$ & 200 & 780 & 16 & 294 & 18 & 11 & 1085 & 42,5 & 25,5294118 \\
\hline $12.30-12.45$ & 200 & 729 & 17 & 308 & 18 & 10 & 1047 & 41,17647 & 25,4271429 \\
\hline $12.45-13.00$ & 200 & 721 & 18 & 322 & 18 & 13 & 1056 & 40 & 26,4 \\
\hline $13.00-13.15$ & 200 & 764 & 17 & 287 & 21 & 8 & 1059 & 38,31933 & 27,6361842 \\
\hline $13.15-13.30$ & 200 & 789 & 18 & 301 & 22 & 8 & 1098 & 36,36364 & 30,195 \\
\hline $13.30-13.45$ & 200 & 824 & 18 & 348 & 18 & 7 & 1179 & 40 & 29,475 \\
\hline $13.45-14.00$ & 200 & 814 & 18 & 287 & 18 & 8 & 1109 & 40 & 27,725 \\
\hline
\end{tabular}

Tabel 4. Hasil observasi langsung arah Thamrin - Monas jam $17.00-19.00$

\begin{tabular}{cccccccccc}
\hline \multirow{2}{*}{ Waktu } & \multirow{2}{*}{$\begin{array}{c}\text { Jarak } \\
(\mathrm{m})\end{array}$} & \multicolumn{2}{c}{ Motor } & \multicolumn{7}{c}{ Mobil } & \multicolumn{3}{c}{ Bus/Truck } & Q & $\mathrm{T}$ & Total & $\begin{array}{c}\mathrm{T} \\
(\mathrm{s})\end{array}$ & Total & & $\overline{\mathrm{V}}$ & $\mathrm{Q} / \overline{\mathrm{V}}$ \\
\hline $17.00-17.15$ & 200 & 946 & 16 & 389 & 18 & 3 & 1338 & 42,5 & 31,4823529 \\
\hline $17.15-17.30$ & 200 & 920 & 16 & 374 & 19 & 3 & 1297 & 41,44737 & 31,2926984 \\
\hline $17.30-17.45$ & 200 & 988 & 16 & 391 & 19 & 4 & 1383 & 41,44737 & 33,367619 \\
\hline $17.45-18.00$ & 200 & 1027 & 17 & 425 & 19 & 5 & 1457 & 40,12384 & 36,3125772 \\
\hline $18.00-18.15$ & 200 & 1009 & 17 & 407 & 18 & 2 & 1418 & 41,17647 & 34,4371429 \\
\hline $18.15-18.30$ & 200 & 994 & 17 & 453 & 19 & 2 & 1449 & 40,12384 & 36,1131944 \\
\hline $18.30-18.45$ & 200 & 1045 & 18 & 411 & 19 & 1 & 1457 & 38,94737 & 37,4094595 \\
\hline $18.45-19.00$ & 200 & 971 & 17 & 400 & 18 & 2 & 1373 & 41,17647 & 33,3442857 \\
\hline
\end{tabular}

Kemudian untuk hasil V (kecepatan rata - rata) dan Q/V (kepadatan) akan dibuat dalam persamaan regresi linear yaitu grafiUntuk setiap hasil observasi langsung akan dimasukkan kedalam regresi linear seperti gambar dibawah ini. 


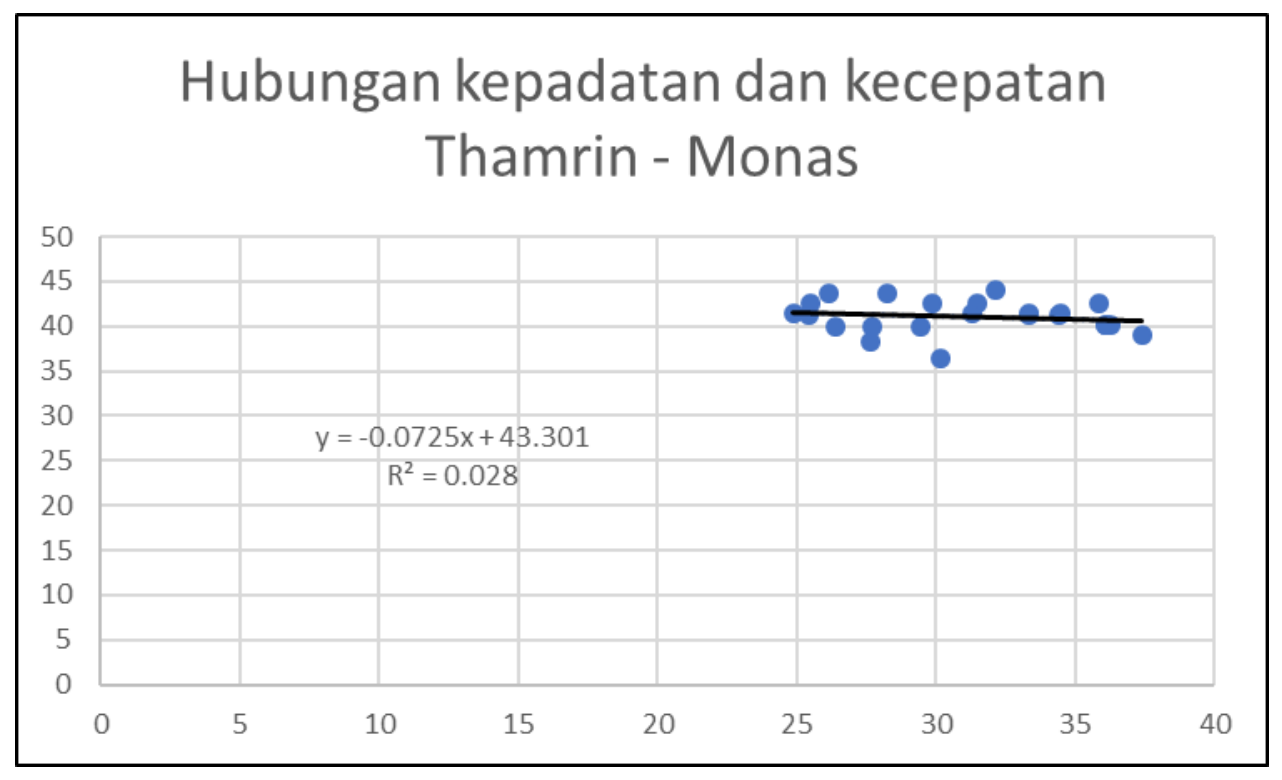

Gambar 1. Grafik hubungan kepadatan dan kecepatan arah Thamrin - Monas

Data tersebut diambil ketika saat jam sibuk sedang berlangsung sehingga hasil yang didapat merupakan hasil yang menuju titik tertinggi dari garis hubungan antara kecepatan dan volume lalu lintas. Dari data yang telah disajikan tersebut juga mengalami reduksi akibat adanya hambatan samping seperti parkir, orang menyebrang, kendaraan tidak bermotor, dan berhenti dipinggir jalan.Pada seluruh data yang disajikan dapat dilihat bahwa pada pukul $12.00-14.00$ memiliki volume kendaraan paling rendah dibandingkan pagi 06.00 dan 17.00. Pada setiap waktu dan ruas jalan memiliki rata - rata kecepatan yang kurang lebih sama.

Hasil pengumpulan data hambatan samping yang akan dilihat yaitu kendaraan tidak bermotor, kendaraan yang berhenti, kendaraan yang keluar masuk, dan pejalan kaki yang menyeberang sepanjang 200 meter pada pukul 07.00 09.00, 13.00 - 15.00, 16.00 - 18.00. Data yang didapat kemudian dikalikan faktor hambatan sampingnya. Untuk kendaraan tidak bermotor dikalikan 0,4 , pejalan kaki yang menyeberang 0,5 , kendaraan yang keluar / masuk 0,7 , dan kendaraan yang parkir 1. Hasil dari kapasitas jalan dapat dilihat pada tabel 5. Data yang sudah dikalikan dengan pemfaktorannya kemudian ditentukan kode hambatannya. Kemudian menghitung kapasitas dengan rumus sebagai berikut:

$$
\mathrm{C}=\mathrm{Co} \times \mathrm{F}_{\mathrm{CW}} \times \mathrm{F}_{\mathrm{CSP}} \times \mathrm{F}_{\mathrm{CSF}} \times \mathrm{F}_{\mathrm{CCS}}
$$

Dengan $\mathrm{C}=$ Kapasitas $(\mathrm{smp} / \mathrm{jam}), \mathrm{Co}=$ Kapasitas dasar $(\mathrm{smp} / \mathrm{jam})$, biasanya digunakan angka $2300 \mathrm{smp} / \mathrm{jam}, \mathrm{F}_{\mathrm{CW}}=$ Faktor penyesuaian lebar jalan, $\mathrm{F}_{\mathrm{CSP}}=$ Faktor penyesuaian pemisahan arah (hanya utk jalan tak terbagi), $\mathrm{F}_{\mathrm{CSF}}=$ Faktor penyesuaian hambatan samping dan bahu jalan/kereb, $\mathrm{F}_{\mathrm{CCS}}=$ Faktor penyesuaian ukuran kota

Tabel 5. Kapasitas jalan arah Thamrin - Sudirman

\begin{tabular}{ccccccccc}
\hline Waktu & Jarak & $\begin{array}{c}\text { Kendaraan tidak } \\
\text { bermotor }\end{array}$ & $\begin{array}{c}\text { Pejalan } \\
\text { kaki }\end{array}$ & $\begin{array}{c}\text { Keluar } \\
\text { masuk }\end{array}$ & Parkir & Hambatan & $\begin{array}{c}\text { Kelas } \\
\text { Hambatan }\end{array}$ & C \\
\hline $06.00-08.00$ & 200 & 5 & 49 & 13 & 2 & 37.6 & VL & 4223,7 \\
\hline $12.00-14.00$ & 200 & 7 & 64 & 11 & 5 & 47.5 & VL & 4223,7 \\
\hline $17.00-19.00$ & 200 & 3 & 61 & 19 & 4 & 49 & VL & 4223,7 \\
\hline
\end{tabular}

Setelah menganalisi observasi langsung pengujian kuesioner adalah hal yang perlu dilakukan. Pengujian yang dilakukan dalam penelitian ini yaitu pengujian validitas dan pengujian regresi linear berganda. Data hasil penyebaran 
kuesioner yang dikumpulkan akan dianalisis dengan menggunakan uji validitas dan akan dibantu dengan menggunakan program IBM SPSS versi 22.0. Dijalankan analisis tersebut dikarenakan untuk mengetahui hasil dari penyebaran kuesioner tersebut valid atau tidak. Uji validitas dilakukan dengan menggunakan program SPSS. Hasil dari output akan dinyatakan valid jika nilai Pearson Correlation lebih besar dari nilai $\mathrm{r}$ tabel. Untuk nilai $\mathrm{N}$ responden berjumlah 50 dengan taraf signifikan 5\% maka nilainya yaitu 0,2732 yang dapat dilihat pada tabel 6 dibawah ini.

Tabel 6. $r$ Tabel

\begin{tabular}{rrrrrr}
\hline 45 & 0,2429 & 0,2876 & 0,3384 & 0,3721 & 0,4647 \\
\hline 46 & 0,2403 & 0,2845 & 0,3348 & 0,3683 & 0,4601 \\
\hline 47 & 0,2377 & 0,2816 & 0,3314 & 0,3646 & 0,4557 \\
\hline 48 & 0,2353 & 0,2787 & 0,3281 & 0,361 & 0,4514 \\
\hline 49 & 0,2329 & 0,2759 & 0,3249 & 0,3575 & 0,4473 \\
\hline 50 & 0,2306 & 0,2732 & 0,3218 & 0,3542 & 0,4432 \\
\hline
\end{tabular}

Hasil dari pengujian validitas untuk pemilihan tarif dan waktu dapat dilihat pada tabel 7 dengan melihat nilai distribusi nilai r. Jika nilai rhitung $>0,2732$ maka valid dan dapat digunakan.

Tabel 7. Uji Validitas

\begin{tabular}{ccccc}
\hline No. item & rhitung & rtabel 5\% & Sig & Kriteria \\
\hline Pertanyaan 1 & 0,281 & 0,2732 & 0,048 & VALID \\
\hline Pertanyaan 2 & 0,34 & 0,2732 & 0,016 & VALID \\
\hline Pertanyaan 3 & 0,361 & 0,2732 & 0,01 & VALID \\
\hline Pertanyaan 4 & 0,483 & 0,2732 & 0 & VALID \\
\hline Pertanyaan 5 & 0,299 & 0,2732 & 0,035 & VALID \\
\hline Pertanyaan 6 & 0,299 & 0,2732 & 0,035 & VALID \\
\hline
\end{tabular}

Dari tabel dapat dilihat bahwa semua data VALID (dapat digunakan). Perbandingan rhitung > rtabel dan dapat dilihat uji validitas Pearson pada tabel lampiran.

Setelah melakukan uji validitas, akan dilakukan pengujian regresi linear berganda yang digunakan untuk menguji pengaruh dua variable bebas terhadap variable terikat. Bila nilai signifikan kurang dari $0,05(5 \%)$ berarti variabel $\mathrm{X}$ berpengaruh terhadap variabel Y. Dimana X1 yaitu harga, X2 yaitu waktu dan Y yaitu pilihan. Digunakan tingkat kepercayaan $\alpha=0,05$. Setelah dimasukan kedalam program SPSS didapatkan hasil sebagai berikut ini.

Tabel 8. Uji hipotesis $\mathrm{H} 1$ dan $\mathrm{H} 2$ dengan uji $\mathrm{t}$

\section{Coefficients $^{a}$}

\begin{tabular}{|c|c|c|c|c|c|c|}
\hline & \multirow{2}{*}{ Model } & \multicolumn{2}{|c|}{$\begin{array}{c}\text { Unstandardized } \\
\text { Coefficients }\end{array}$} & \multirow{2}{*}{$\begin{array}{c}\text { Standardized } \\
\text { Coefficients }\end{array}$} & \multirow{2}{*}{$\mathrm{t}$} & \multirow{2}{*}{ Sig. } \\
\hline & & B & $\begin{array}{c}\text { Std. } \\
\text { Error }\end{array}$ & & & \\
\hline \multirow{3}{*}{1} & $($ Constant $)$ & 0,887 & 0,038 & & 23,243 & 0 \\
\hline & $\mathrm{X} 1$ & 0,017 & 0,007 & 1,106 & 2,354 & 0,019 \\
\hline & $\mathrm{X} 2$ & $-0,035$ & 0,009 & $-1,823$ & $-3,88$ & 0 \\
\hline
\end{tabular}


Dari tabel $\mathrm{t}$ di dapat dengan menggunakan rumus $\mathrm{t}(\alpha / 2 ; \mathrm{n}-\mathrm{k}-1)$ dan didapatkan hasil $\mathrm{t}(0,025 ; 47)=2,01174$. Karena $\mathrm{X} 1$ memiliki nilai $\mathrm{t}>2,01174$ dan nilai signifikan $<0,05$ maka dapat disimpulkan bahwa terdapat pengaruh X1 terhadap Y. X2 memiliki nilai t $<2,01174$ dan nilai signifikan $<0.05$ maka dapat disimpulkan bahwa tidak terdapat pengaruh X2 terhadap Y, dan dapat dilihat hasilnya pada tabel 9.

Tabel 9. Uji H3 dengan uji F

\begin{tabular}{|c|c|c|c|c|c|c|}
\hline \multicolumn{7}{|c|}{ ANOVA $^{\mathrm{a}}$} \\
\hline \multicolumn{2}{|c|}{ Model } & $\begin{array}{l}\text { Sum of } \\
\text { Squares }\end{array}$ & $\mathrm{df}$ & $\begin{array}{l}\text { Mean } \\
\text { Square }\end{array}$ & F & Sig. \\
\hline \multirow{3}{*}{1} & Regression & 11,597 & 2 & 5,798 & 166,782 &, $000^{\mathrm{b}}$ \\
\hline & Residual & 10,326 & 297 & 0,035 & & \\
\hline & Total & 21,922 & 299 & & & \\
\hline
\end{tabular}

Dari tabel F di dapat dengan menggunakan rumus F (k; n-k) maka didapatkan hasil F $(2 ; 48)=3,19$. Maka dapat disimpulkan bahwa hipotesis ketiga diterima dikarenakan 166,782 > 3,19 dan terdapat pengaruh X1 dan X2 secara simultan terhadap Y dan dapat dilihat pada tabel 10.

Tabel 10. Koefisien diterminasi

\begin{tabular}{ccccc}
\multicolumn{5}{c}{ Model Summary } \\
\hline Model & $R$ & $R$ Square & $\begin{array}{c}\text { Adjusted } \\
R \text { Square }\end{array}$ & $\begin{array}{c}\text { Std. Error of the } \\
\text { Estimate }\end{array}$ \\
\hline 1 &, $727^{\mathrm{a}}$ & 0,529 & 0,526 & 0,18646 \\
\hline
\end{tabular}

Berdasarakan hal ini dapat diartikan bahwa pengaruh variabel X1 dan X2 secara simultan terhadap variabel Y adalah sebesar 52,9\%. Dari kuesioner yang telah dimasukan kedalam program SPSS dengan menggunakan analisis regresi linear didapatkan persamaan sebagai berikut:

$$
\text { Perp }=0,887+0,017 \mathrm{X} 1-0,035 \mathrm{X} 2
$$

Pada analisis ini akan diketahui nilai penurunan $\mathrm{Q} / \mathrm{V}$ dalam persen dan akan dimasukan kedalam grafik hubungan kecepatan dan kepadatan. Variabel X1 menunjukkan harga dan variabel X2 menunjukan waktu. Perp yang bernilai 1 akan memiliki koefisien sebesar 1, bila bernilai 2 akan memiliki koefisien sebesar 0,8 , bila bernilai 3 akan memiliki koefisien sebesar 0,5, dan bila bernilai 4 akan memiliki koefisien sebesar 0,2. Nilai koefisien akan diinterpolasi bila memiliki nilai yang tidak bulat. Hasil dari perkalian persamaan dapat dilihat pada tabel 11 .

Tabel 11. Tabel $P_{\text {erp }}$

\begin{tabular}{|c|c|c|c|c|}
\hline \multicolumn{4}{|c|}{ Perp $=0,887+0,017 \mathrm{X} 1-0,035 \mathrm{X} 2$} & \multirow{2}{*}{ Koef } \\
\hline $\mathrm{Y}$ & $\mathrm{X} 1$ & $\mathrm{X} 2$ & Perp & \\
\hline 0.887 & 15 & 10 & 1.492 & 0.9016 \\
\hline 0.887 & 30 & 20 & 2.097 & 0.7709 \\
\hline 0.887 & 40 & 30 & 2.617 & 0.6149 \\
\hline 0.887 & 50 & 40 & 3.137 & 0.4589 \\
\hline 0.887 & 60 & 45 & 3.482 & 0.3554 \\
\hline 0.887 & 65 & 50 & 3.742 & 0.2774 \\
\hline
\end{tabular}


Koefisien yang didapat akan dikalikan dengan Q/V pada grafik hubungan kecepatan dan kepadatan pada ruas jalan yang telah dibuat sebelumnya. Pada permodelan ini akan hanya menyajikan ERP dengan harga 15.000, 30.000, dan 40.000. Ini dikarenakan responden lebih banyak memilih pilihan harga tersebut.

Tabel 12. Tabel perbandingan kepadatan, kecepatan dan volume dengan rekayasa ERP pada ruas Thamrin - Sudirman

\begin{tabular}{ccccccc}
\hline Harga & D awal & V awal & Volume awal & D erp & V erp & Volume erp \\
\hline \multirow{3}{*}{15.000} & 24,899 & 41,4474 & 1032 & 22,449 & 41,6734 & 935,5264754 \\
\cline { 2 - 7 } & 31,2927 & 41,4474 & 1297 & 28,2135 & 41,2555 & 1163,962527 \\
\cline { 2 - 7 } & 37,4095 & 38,9474 & 1457 & 33,7284 & 40,8557 & 1377,995884 \\
\hline \multirow{3}{*}{30.000} & 24,899 & 41,4474 & 1032 & 19,1947 & 41,9094 & 804,4370777 \\
\cline { 2 - 7 } & 31,2927 & 41,4474 & 1297 & 24,1235 & 41,552 & 1002,382428 \\
\hline \multirow{3}{*}{45.000} & 37,4095 & 38,9474 & 1457 & 28,839 & 41,2102 & 1188,458299 \\
\cline { 2 - 7 } & 24,899 & 41,4474 & 1032 & 15,3104 & 42,191 & 645,9620268 \\
\hline & 31,2927 & 41,4474 & 1297 & 19,2419 & 41,906 & 806,3495351 \\
\hline
\end{tabular}

Pada model ERP diambil nilai kepadatan terbesar, terkecil dan sedang untuk dimodelkan kembali kedalam grafik hubungan antara kepadatan dan kecepatan untuk masing - masing ruas jalan. Angka penurunan kepadatan memberikan efek yang berbeda terhadap kecepatan dan volume lalu lintas. Dapat dilihat pada tabel diatas.

\section{KESIMPULAN DAN SARAN}

\section{Kesimpulan:}

1. Dari hasil pengamatan langsung dapat diketahui bahwa peningkatan volume kendaraan terjadi pada pagi hari dan pada malam hari. Hal ini dikarenakan pengguna jalan lebih banyak digunakan saat jam kerja dan pulang kerja.

2. Dari hasil kuesioner yang telah disebar dapat diketahui bahwa responden lebih cenderung memilih harga Electronic Road Pricing pada kisaran harga Rp 15.000 sampai dengan Rp 45.000.

3. Dari hasil analisis yang sudah dihitung dapat disimpulkan bahwa harga Rp 30.000 merupakan harga yang sesuai untuk mengurangi kemacetan pada ruas jalan Blok M - Kota dan harga yang paling efektif untuk mengurangi kemacetan. Selain dari analisis, hasil kuesioner juga berpengaruh dalam kesimpulan ini dikarenakan semua responden tidak ada yang memilih untuk tidak melewati jalan bila ERP sudah diterapkan.

\section{Saran:}

1. Penelitian yang sama perlu dilakukan pada ruas-ruas jalan yang saat ini diberlakukan ganjil genap.

2. Perlu melakukan survei lalu lintas satu hari penuh untuk mendapatkan lebih banyak variasi kondisi lalu lintas.

\section{DAFTAR PUSTAKA}

Admin.”TransJakarta Busway Blok M - Kota”. 26 Juli. 2019: http://www.transportumum.com/jakarta/transjakartablok-m-kota/

Authority, Land Transport."Electronic Road Pricing". 19 Juli. 2019: https://www.lta.gov.sg/content/ltaweb/en/roadsand-motoring/managing-traffic-and-congestion/electronic-road-pricing-erp.html

Direktorat Jenderal Bina Marga. "Manual Kapasitas Jalan Indonesia”. Februari 1997.

Elhavidz."Definisi Transportasi Menurut Para Ahli”. 24 Juli. 2019: http://elhavidz.blogspot.com/2015/03/definisihukum-pengangkutan.html

Ortuzar, J.D. and Willumsen, L.G. “Modelling Transport, Second Edition”. John Wiley \& Sons. 1994. 
Paparan PCI, PCKK, dan Sumitimo Corporation, "The Study on Jakarta Road Pricing in the Republic of Indonesia." Rancangan Peraturan Pemerintah Republik Indonesia Tahun 2010 Tentang Lalu Lintas dan Angkutan Jalan 2008.

Statistik, Badan Pusat."Lalu Lintas Darat Dalam Negeri Indonesia Tahun 2017”. 26 Juli. 2019: https://www.bps.go.id/subject/17/transportasi.html

Statistik, Konsultan."Regresi Linear Berganda". 9 Juli. 2019: http://www.konsultanstatistik.com/2009/03/regresilinear.html

Statistikian.”Cara Menggunakan SPSS Sederhana". 28 November. 2019: https://www.statistikian.com/ 